\title{
Motivação para a prática desportiva nos alunos do ensino básico e secundário: Influência do género, idade e nível de escolaridade
}

\author{
Students motivations for sport involvement: The effect of age, gender \\ and school level
}

\author{
N. Januário, C. Colaço, A. Rosado, V. Ferreira, R. Gil
}

ARTIGO ORIGINAL | ORIGINAL ARTICLE

\begin{abstract}
RESUMO
O presente estudo investigou a relação entre os motivos para a prática desportiva e as características dos alunos como o género, idade e nível de escolaridade. A amostra foi constituída por 1016 alunos da área da Grande Lisboa (577 do género masculino e 439 do feminino, com idades entre os 10 e os 20 anos). Os dados foram obtidos através da aplicação do QMAD (Frias \& Serpa, 1991). Na análise dos dados, foi realizada uma análise fatorial de componentes principais que revelou seis fatores. Foram utilizadas estatísticas descritivas e os testes comparativos Anova e Bonferroni. As motivações mais valorizadas para a prática desportiva foram Aprendizagem Técnica/Fitness e Trabalho de Equipa e a menos valorizada foi o Estatuto. A comparação em função do género e dos níveis de ensino dos alunos revelou diferenças significativas. Identificaram-se associações estatisticamente significativas entre alguns fatores motivacionais e a idade dos alunos.

Palavras-chave: motivação, prática desportiva, género, idade, nível de escolaridade
\end{abstract}

ABSTRACT

The aim of this study was to identify student's motivations for sport involvement according with student's characteristics as gender, age and school level. The subjects were 1016 students, from ten different schools from the Lisbon metropolitan area, (577 male and 439 female; between 10 and 20 years old). We used a five points Likert type questionnaire with 30 items, a Portuguese version of the PMQ developed by Gill et al. (1983), translated and validated by Frias and Serpa (1991). A principal component analysis for the evaluation of the scale was done, and Descriptive statistics, Anova and Bonferroni test were used. The results showed that, globally, the most valorised motivations for participation in physical activity were reasons related with Fitness/Technical Achievement and Team Work and the less indicated motive was Status. Comparing motivational factors according to student's school level and gender we found significant differences. Several motivational factors were significantly influenced by students' age.

Keywords: motivation, sports practices, gender, age, school level

Submetido: 08.09.2011 | Aceite: 02.12.2012

Nuno Januário, Carlos Colaço, António Rosado, Vitor Ferreira e Rosimeiri Gil. Faculdade de Motricidade Humana, Universidade Técnica de Lisboa, Lisboa, Portugal.

Endereço para correspondência: Nuno Januário, Departamento de Ciências do Desporto, Faculdade de Motricidade Humana, Estrada da Costa, Cruz Quebrada, 1499 Lisboa Codex, Portugal.

E-mail: njanuario@fmh.utl.pt 
A descrição das razões que as populações apresentam para serem fisicamente ativas através do desporto e os seus motivos de participação é um ponto de partida muito útil para entender a sua motivação e, em função desse conhecimento, organizar e diferenciar a oferta desportiva. O conhecimento da relação entre a prática motora e o conjunto das motivações dos praticantes de atividades físicas é essencial para a intervenção do profissional desta área (Paim \& Pereira, 2004). Para que professores, técnicos e gestores desportivos consigam manter a permanência, adesão e aumento do número de praticantes é necessário o uso de instrumentos que possibilitem, com segurança, determinar os motivos que levam as pessoas a praticá-las (Barroso, Araújo, Keulen, Braga, \& Krebs, 2007). Na realidade, conhecer a motivação desportiva da população, em função das suas características demográficas, é fundamental para que se possa planear o seu correto acompanhamento e, simultaneamente, conseguir elementos fundamentais para a gestão cuidada das diferentes ações de desenvolvimento e promoção das atividades desportivas, nomeadamente, permitindo a sua segmentação e a consequente oferta de serviços desportivos de maior qualidade.

Perceber as motivações para a prática desportiva é um elemento essencial para traçar o caminho mais correto, isto é, para planear o futuro. O trabalho a levar a efeito pelos diversos profissionais da área está sempre dependente dos motivos que levam a diferentes escolhas ou até à não escolha de qualquer atividade desportiva.

De acordo com Samulsky (1992), a motivação é caracterizada como um processo ativo, intencional e dirigido a uma meta, o qual depende da interação de fatores pessoais e ambientais. Neste âmbito, a motivação apresenta uma determinante energética (nível de ativação ou intensidade) que diz respeito à forma como o atleta se envolve na atividade e uma determinante de direção do comporta- mento (intenções, interesses e motivos).

Em matéria de motivos conducentes à prática desportiva, a pesquisa tem encontrado um diverso número de motivos, incluindo divertimento, aspectos sociais e desenvolvimento de habilidades (Biddle, 1998).

O estudo dos intuitos que levam as pessoas a praticar uma atividade desportiva, iniciado nos finais da década de 70 (Alderman, 1976, 1978; Alderman \& Wood, 1976), tem reunido um grande interesse ao nível da literatura específica da psicologia do desporto e tem sido concretizado na realização de um elevado número de investigações em diversos países (Allen, 2003; Barroso et al., 2007; Kilpatrick, Hebert, \& Bartholomew, 2005; Lores, Murcia, Sanmartín, \& Camacho, 2004; Machado, Piccoli, \& Scalon, 2005; Marzinek \& Neto, 2007; Sirard, Pfeiffer, \& Pate, 2006). Para tal contribuiu, de forma significativa, o Participation Motivation Questionnaire (PMQ), desenvolvido por Gill, Gross, e Huddleston (1983), instrumento que permite avaliar os motivos mais importantes para a prática desportiva. No entanto, talvez devido ao facto de o PMQ ter sido desenvolvido em língua inglesa, a maior parte dos estudos referidos na literatura têm sido realizados em países anglo-saxónicos, exigindo-se, deste modo, a necessidade de validação à população portuguesa. Em Portugal, os estudos têm também vindo a aumentar (Cid, 2002; Cruz, Costa, Rodrigues, \& Ribeiro, 1988; Fonseca \& Fontaínhas, 1993; Fonseca \& Ribeiro, 2001; Serpa, 1992). Em particular, Gill et al. (1983) avaliaram os motivos de participação através do PMQ. De acordo com os autores, os motivos agrupam-se em categorias ou dimensões motivacionais, tais como, Estatuto, Forma Física, Competição, Afiliação Geral, Desenvolvimento Técnico, Afiliação Específica/Equipa, Emoções e Prazer/ Ocupação dos Tempos Livres e, de um ponto de vista mais geral, em quatro dimensões motivacionais mais abrangentes: Competências Físico-Desportivas (constituída pelas dimensões da Forma Física e do Desenvolvimento 
Técnico), Afiliação (constituída pelas dimensões da Afiliação Geral e da Afiliação Específica/Equipa), Realização (constituída pelas dimensões do Estatuto, das Emoções e do Prazer/Ocupação dos Tempos Livres) e Competição.

A primeira análise extensiva sobre motivação foi realizada por Sapp e Haubenstricker (1978) com uma amostra de 579 rapazes e 471 raparigas, com idades entre os 11 e os 18 anos, praticantes de 11 modalidades desportivas. Os resultados mostraram que uma elevadíssima percentagem dos atletas participava nas atividades pelo divertimento proporcionado (90\%), $80 \%$ porque ansiavam evoluir nas suas competências e $56 \%$ estavam preocupados com os aspectos ligados à saúde/aptidão física.

Fry, McClements, e Sefton (1981) verificaram, junto de jovens atletas praticantes de hóquei no gelo, que $98 \%$ esperavam divertir-se muito com o jogo, $87 \%$ desejavam tornar-se bons praticantes, $68 \%$ desejavam fazer novas amizades, $61 \%$ ambicionavam conquistar troféus e $54 \%$ esperavam fazer exercício físico e viajar.

Gould, Feltz, Weiss, e Petlichkoff (1982) inquiriram 365 jovens nadadores de competição, com idades compreendidas entre os nove e os 18 anos, sobre os motivos para a participação na sua atividade desportiva, tendo sido referenciados, o divertimento, a forma física, a saúde física, a melhoria de competências, a "atmosfera" da equipa e o desafio. Por outro lado, os que tiveram menos influência na sua participação foram: Agradar aos pais ou aos melhores amigos, acalmar a tensão, ser popular e viajar.

Klint e Weiss (1987) concluíram que os motivos invocados como mais importantes para a prática desportiva foram: Aprender novas competências, adquirir a forma física, melhorar as competências, divertimento, estar em forma, gosto pelo desafio, prazer no uso dos equipamentos e competir ao mais alto nível. Como menos importantes foram mencionados:
Influência dos amigos, libertar energias, gostar de ser popular, ser conhecido e ter um pretexto para sair de casa.

Gill et al. (1983) estudaram as razões de 720 rapazes e 418 raparigas, praticantes de basquetebol, luta, futebol, golfe, basebol, ténis, atletismo, futebol, ginástica e voleibol, com idades compreendidas entre os oito e os 18 anos, para a adesão a uma atividade desportiva. Os resultados demonstraram como motivos mais fortes: Melhorar as competências, divertimento, aprender novas competências, desafio e ser fisicamente saudável.

Cruz et al. (1988), num estudo realizado em Portugal, constataram que os atletas foram atraídos para a prática do andebol por motivos relacionados com o desenvolvimento das suas capacidades e manutenção e/ou promoção da saúde/forma física, assim como pelo divertimento e pela descarga de energia.

Também Serpa (1992) pesquisou os motivos que levaram 175 jovens (85 rapazes e 90 raparigas), com idades entre os 10 e os 15 anos, a envolverem-se numa atividade desportiva. Os motivos mais frequentemente apontados foram: Estar em boa condição física, trabalhar em equipa, aprender novas técnicas, espírito de equipa, fazer exercício, manter a forma, atingir um nível desportivo mais elevado, melhorar as capacidades técnicas e fazer novas amizades. Fonseca e Fontaínhas (1993) constataram, como principais motivos para a prática, a possibilidade de desenvolver a sua capacidade técnica e de manter a condição física.

Por seu lado, Santana e Mota (1994), efetuando um estudo sobre os motivos que levaram 497 indivíduos a praticarem natação, indicaram, como fundamentais, a condição física e a libertação de energias. Fonseca e Soares (2001) destacaram como mais importantes os motivos relativos à forma física e ao desenvolvimento de competências, e, em segundo plano, os ligados à afiliação específica e geral. Por outro lado, os motivos relacionados com o estatuto, com as emoções e com 
o prazer/ocupação dos tempos livres foram os menos referenciados.

Cid (2002) utilizou uma amostra composta por 110 sujeitos do sexo masculino, com idades compreendidas entre os 15 e 20 anos, tendo concluído que os motivos mais importantes eram manter a forma, estar em boa condição física, prazer e divertimento.

Machado et al. (2005), num estudo realizado no Brasil, com uma amostra de 102 adolescentes, de ambos os sexos, na faixa etária de 14 a 17 anos, identificou, como fatores motivacionais mais importantes para a prática desportiva, o divertimento e a saúde, referindo os autores que parece que os adolescentes se motivam mais à prática regular da atividade física quando o prazer está associado a essa prática.

O estudo realizado por Ullrich-French e Smith (2006) com uma amostra de 1719 jogadores de futebol, de ambos os sexos e com idades variando de 12 a 19 anos, concluiu que o bom relacionamento e aceitação pelos pares ou pelos pais, fazem com que os adolescentes sintam um maior prazer pela atividade praticada.

Esta diversidade dá conta da multiplicidade de motivos conducentes à prática desportiva. No entanto, simplesmente descrever os motivos não fornece informação suficiente para os distinguir em função de características diferenciadoras da população. Entre essas características, especialmente significativas para os agentes desportivos, encontram-se o género, a idade e os níveis de escolaridade.

Motivação e género. De acordo com Fonseca (1995), a influência das características sexuais dos sujeitos nos seus rendimentos, percepções ou preferências é um dos assuntos mais estudados pelos investigadores, inserindo-se, também, neste grupo, eventuais diferenças em função do género dos inquiridos no que concerne aos motivos para a prática desportiva. Desta forma, as raparigas parecem ter motivos diferentes dos rapazes para a prática desportiva, concedendo mais importância a motivos rela- cionados com a amizade e a afiliação e menos importância a motivos relacionados com a competição, estatuto e reconhecimento. Em relação aos motivos relacionados com aprendizagem ou melhoramento de capacidades, parece existir alguma inconsistência entre as conclusões das diversas investigações desenvolvidas em Portugal, isto porque, enquanto alguns estudos referem que eles são mais importantes para os rapazes, outros sublinham exatamente o contrário.

Machado et al. (2005) referem que os sujeitos do sexo masculino indicaram como motivo principal para a prática de atividade física motivos relacionados com a saúde, enquanto o sexo feminino referiu o divertimento.

Motivação e Idade. A variável idade manifesta-se de formas diferentes nos motivos assinalados para a prática desportiva. Fernandes (2001) refere que existem diferenças significativas entre os motivos referidos por nadadores mais novos face aos mais velhos, sendo que os mais novos atribuem valores significativamente mais altos à Afiliação Geral e à Afiliação Específica. Contudo, Fonseca, Freitas, e Frade (1998), numa amostra de 183 sujeitos, concluíram que os atletas de futebol mais velhos (escalões de juvenis e juniores) atribuíam maior importância aos motivos relacionados com a Afiliação Geral ao passo que os mais novos (escalões de infantis e iniciados) valoravam mais a Afiliação Específica.

Também Afonso, Fernandes, Soares, e Fonseca (2001) numa amostra de 60 praticantes de aeróbia, com idade entre os 12 e os 51 anos, verificaram que as raparigas de idade inferior a 19 anos valorizavam mais os motivos relacionados com a Forma Física e o Prazer.

Fonseca e Fontaínhas (1993), numa amostra de 50 sujeitos, verificaram diferenças significativas nos motivos mais valorizados considerando a idade. Assim, os mais novos deram mais importância aos aspectos relacionados com o Estatuto, Grupo, Libertação de Energia, 
Divertimento, Amigos e Outros. Num estudo em Natação, Rebelo e Mota (1994) referem que os mais novos (com idades compreendidas entre os 16 e os 25 anos) assinalam que praticam a modalidade como forma de fazer amizades, de ultrapassar desafios e de divertimento.

Balbinotti, Barbosa, Juchem, Balbinotti, \& Saldanha (2007), num estudo realizado com uma amostra de 428 adolescentes do sexo masculino, com idades entre 13 e 16 anos, concluíram que a motivação à prática regular de atividade física relacionada com o prazer não varia, de forma significativa, durante a adolescência.

A literatura sobre a influência da idade na estrutura motivacional não parece ser, ainda, como se constata, totalmente clara. No sentido de se estudar melhor este aspecto, introduziu-se, no estudo, a diferenciação da estrutura motivacional em função da idade e do nível de escolaridade, variável que, co-variando no essencial com a idade, não tem sido objeto de estudo, mas permite organizar um cluster de motivações em torno de um critério de reconhecível pertinência social.

Finalmente, muita da pesquisa sobre os motivos para a participação tem sido concretizada usando variações do PMQ de Gill et al. (1983). O PMQ tem sido utilizado e adaptado nos diversos contextos do desporto, do exercício (Trembath, Szabo, \& Baxter, 2002), da atividade física (Kolt, Driver, \& Giles, 2004) e da Educação Física (Zahariadis \& Biddle, 2000) mas o número de factores e mesmo os itens componentes em resultado de diversas análises factoriais, tem variado em função das amostras em investigação (Gill, Gross, \& Huddleston, 1983; Koivula, 1999). Como tal, cada uso do questionário parece requerer a identificação desses fatores e da sua fiabilidade.

Neste sentido, um dos objetivos deste trabalho foi reexaminar a estrutura fatorial da escala na sua versão portuguesa.

A estrutura da motivação para as práticas desportivas numa sociedade em rápida e constante mutação, com alteração muito rápida das condições sociais, culturais e de ocupação dos tempo livres justifica alterações significativas nos motivos de procura da prática desportiva, pelo que a análise regular dos motivos dos jovens para essa prática deve ser monitorizada com regularidade. Na sequência desta análise, colocam-se as seguintes questões:

- Qual é o perfil geral de motivos de participação desportiva dos jovens?

- Serão os motivos para participar diferenciados em função do género dos praticantes, da sua idade e do seu nível de escolaridade?

Os professores, os pais, os responsáveis pela promoção e desenvolvimento do desporto podem beneficiar muito de uma resposta clara a esta questão. $\mathrm{O}$ conhecimento dos tipos de motivação pode encorajar adaptações e ofertas de serviços mais específicos, permitindo experiências mais gratificantes de participação desportiva.

\section{MÉTODO}

\section{Amostra}

Participaram 1016 alunos de dez escolas, da região da Grande Lisboa, sendo 577 do género masculino e 439 do feminino, com idades compreendidas entre os 10 e 20 anos e cujos níveis de escolaridade eram 283 do segundo ciclo de escolaridade, 416 do terceiro ciclo de escolaridade e 317 do ensino secundário.

\section{Instrumentos}

Neste estudo foi utilizado o Questionário "Motivações para as Atividades Desportivas" (QMAD), tradução da versão original do PMQ (Gill et al., 1983), versão traduzida e adaptada por Frias e Serpa (1991). Este questionário é composto por 30 itens, descrevendo, cada um deles, motivos para a atividade desportiva, aos quais foram atribuídos, numa escala tipo Likert (de 1 a 5), os seguintes níveis: (1 - Nada importante; 2 - Pouco importante; 3 - Importante; 4 Muito importante; 5 - Totalmente importante). 
De acordo com estudos anteriores (Fonseca, 1995; Fonseca \& Maia, 1996), os 30 itens que constituem o PMQ agruparam-se em oito dimensões motivacionais, mas, a estrutura fatorial do PMQ tem variado muito de estudo para estudo. Zahariadis e Biddle (2000) referem a existência de seis fatores motivacionais. Pereira e Vasconcelos-Raposo (1998) encontraram, também, uma estrutura fatorial com seis fatores (embora diferentes dos encontrados por Zahariadis e Biddle, 2000). Posteriormente, Trembath et al. (2002) agruparam os 30 itens que constituem o PMQ em oito dimensões motivacionais.

$\mathrm{Na}$ Tabela seguinte estão indicados o número de fatores motivacionais encontrados pelos autores supracitados, bem como a respectiva identificação.

Tabela 1

Fatores motivacionais encontrado pelos diferentes autores (número e identificação)

\begin{tabular}{|c|c|c|}
\hline Autores & $\begin{array}{l}\text { Número } \\
\text { de fatores }\end{array}$ & Fatores \\
\hline $\begin{array}{c}\text { Fonseca } \\
(1995) ; \\
\text { Fonseca e Maia } \\
\quad(1996)\end{array}$ & 8 & $\begin{array}{c}\text { Estatuto, Forma Física, } \\
\text { Competição, Afiliação } \\
\text { Geral, Desenvolvimento } \\
\text { Técnico, Afiliação Espe- } \\
\text { cífica/Equipa, Emoções, } \\
\text { Prazer/Ocupação dos } \\
\text { Tempos Livres }\end{array}$ \\
\hline $\begin{array}{c}\text { Zahariadis e } \\
\text { Biddle (2000) }\end{array}$ & 6 & $\begin{array}{c}\text { Habilidade/Competição, } \\
\text { Estatuto/Reconheci- } \\
\text { mento, Libertação de } \\
\text { Energia, Atmosfera de } \\
\text { Equipa, Afiliação, Fitness }\end{array}$ \\
\hline $\begin{array}{c}\text { Perreira e } \\
\text { Vasconcelos- } \\
\text {-Raposo (1998) }\end{array}$ & 6 & $\begin{array}{c}\text { Competição, Reconheci- } \\
\text { mento/Estatuto } \\
\text { Amizade/Divertimento, } \\
\text { Descarga de Energia, } \\
\text { Contextual, Outros }\end{array}$ \\
\hline $\begin{array}{l}\text { Trembath, } \\
\text { Szabo e Baxter } \\
\quad(2002)\end{array}$ & 8 & $\begin{array}{c}\text { Orientação para a Equipa, } \\
\text { Orientação para o } \\
\text { Fitness, Orientação para } \\
\text { a Aprendizagem, Fatores } \\
\text { Extrinsecos, Fatores } \\
\text { Mistos, Evitação do Abor } \\
\text { recimento, Popularidade, } \\
\text { Autoaperfeiçoamento }\end{array}$ \\
\hline
\end{tabular}

Esta variabilidade da estrutura fatorial determinou que procedêssemos a uma nova análise fatorial da sua estrutura.

\section{Procedimentos}

Após apresentar-se os objetivos do estudo e depois de obter a autorização dos Conselhos Executivos das respectivas escolas e o consentimento dos alunos, os questionários foram aplicados pela equipa de investigação. Os questionários foram aplicados no início da aula, de modo a evitar um estado emocional exaltado e/ou desatenção proporcionada pelo cansaço. Foi garantida a confidencialidade das respostas, tendo sido reforçado, junto dos alunos, que não existem respostas certas ou erradas, solicitando-se que respondessem de forma sincera. Após isso, foram lidas as instruções, tendo sido retiradas eventuais dúvidas de preenchimento e, só depois, os alunos começaram a preencher o questionário. Quem tivesse dúvidas chamaria o aplicador junto de si a fim de retirar a dúvida.

\section{Análise Estatística}

Os dados recolhidos foram tratados no software SPSS 17.0 (Statistical Package for the Social Sciences), tendo sido realizada uma análise descritiva, calcularam-se as estatísticas descritivas, frequências, percentagens, médias e desvios-padrão. A prova One-Way Anova e as comparações à posteriori, utilizando a prova de Bonferroni, foram utilizadas para explorar as comparações entre grupos. Utilizou-se ainda a Correlação de Spearman. O nível de significância utilizado foi $p \leq 0.05$.

\section{RESULTADOS}

\section{Validação fatorial do PMQ}

Para a avaliação das qualidades psicométricas do instrumento utilizou-se uma análise fatorial de componentes principais exploratória (EFA). De modo a reduzir o número de variáveis e detetar as componentes principais, utilizou-se o método de rotação oblimin, tendo-se exigido 
e verificado diversos requisitos: O número de participantes garantiu que existisse um rácio mínimo de cinco sujeitos por indicador. Considerou-se um valor próprio mínimo de $1.0 \mathrm{e}$ só foram incluídos os fatores compostos pelo mínimo de três itens. Adicionalmente, a prova de Kaiser-Meyer-Olkin $(K M O=0.890)$ e o teste de esfericidade de Bartlett's $(p<.01)$ confirmaram os requisitos para se proceder a uma análise fatorial. Neste âmbito, os scores fatoriais considerados envolveram valores acima de .40 e o alpha de Cronbach foi fixado em .70. Da análise acima referida resultou uma estrutura fatorial com seis fatores motivacionais, que explicam $55.76 \%$ da variância, sendo esta solução suportada, também, pelo scree teste. Na Tabela 2 estão patentes a identificação dos fatores, os itens que o constituem e o valor do Alpha de Cronbach encontrado para cada fator.

A solução fatorial encontrada apresenta algumas dimensões já identificadas em estudos anteriores (Fonseca, 1995; Fonseca \& Maia, 1996; Gill et al. 1983; Pereira \& Vasconcelos-Raposo, 1998; White \& Duda, 1994), no entanto, o fator Aprendizagem Técnica/Fitness nos trabalhos referidos constituíam fatores diferenciados. O fator Influência Extrínseca, encontrado na presente análise fatorial, apesar de não ser referido nos trabalhos anteriormente citados, já tinha sido referenciado por Trembath et al. (2002). A presente análise fatorial excluiu da análise quatro itens $(5,12,17,22)$, dado que estes itens não correspondiam aos critérios para inclusão nos fatores anteriormente referidos.

\section{Determinantes motivacionais para a prática desportiva}

As motivações mais valorizadas para a prática desportiva estavam relacionadas com a Aprendizagem Técnica/Fitness $(M=4.00 ; S D$ $=.65)$, seguindo-se as motivações relacionadas com o Trabalho de Equipa $(M=3.79 ; S D=$ .87). As motivações relacionadas com a Socialização apresentaram o valor médio mais baixo $(M=3.52 ; S D=.81)$. O Estatuto e a Influência Extrínseca apresentaram valores médios relativamente baixos, como se pode constatar na Tabela 3.

Tabela 3

Média e desvio-padrão por fator

\begin{tabular}{cccc}
\hline Fator & $n$ & $\mathrm{M}$ & $\mathrm{SD}$ \\
\hline Técnica/Fitness & 1016 & 4.00 & 0.65 \\
Trabalho de Equipa & 1016 & 3.79 & 0.87 \\
Socialização & 1016 & 3.52 & 0.81 \\
Libertar energia & 1016 & 3.25 & 0.84 \\
Influência Extrínseca & 1016 & 2.70 & 0.84 \\
Estatuto & 1016 & 2.68 & 0.89 \\
\hline
\end{tabular}

Verifica-se que os praticantes apresentavam motivos muito diferenciados para se envolverem nas atividades físicas e desportivas. Os jovens pareciam, de facto, praticar desporto para melhorar a sua capacidade técnica e a forma física, atribuindo pouca importância ao estatuto que a prática desportiva lhes proporciona.

Tabela 2

Identificação dos fatores, itens que os constituem, valores dos Eigenvalues, percentagem de variância explicada pelo fator e Alpha de Cronbach

\begin{tabular}{ccccc}
\hline Fator & Itens & Eigenvalue & \% & $\begin{array}{c}\text { Alpha } \\
\text { Variância explicada }\end{array}$ \\
\hline Estatuto Cronbach \\
\hline Aprendizagem Técnica/Fitness & $1,6,14,20,21,25,28$ & 7.558 & 26.06 & 0.846 \\
Influência Extrínseca & $9,19,27,24,26$ & 2.740 & 9.45 & 0.804 \\
Trabalho de Equipa & $8,11,18$ & 1.972 & 6.80 & 0.645 \\
Libertar Energia & $4,7,13$ & 1.705 & 5.88 & 0.747 \\
Socialização & $2,16,29$ & 1.150 & 3.96 & 0.746 \\
\hline
\end{tabular}




\section{Motivos de Participação em função do Nível de Escolaridade}

Fazendo uma análise das motivações para a prática desportiva em função dos níveis de escolaridade, constatou-se que os alunos do segundo ciclo apresentam a média mais elevada no fator Trabalho de Equipa (3.97), surgindo, imediatamente a seguir, a Aprendizagem Técnica/Fitness que apresenta um valor muito semelhante (3.96). Para os alunos do terceiro ciclo, o valor médio mais elevado regista-se no fator Aprendizagem Técnica/Fitness (4.04), seguindo-se o Trabalho de Equipa com um valor médio de 3.86. No que respeita aos alunos do ensino Secundário, também a Aprendizagem Técnica/Fitness é a que apresentou a média mais elevada (3.98), surgindo, em segundo lugar, a Socialização, que apresentou uma média de 3.60 .

Para todos os níveis de ensino, as dimensões menos importantes são as dimensões Estatuto e Influência Extrínseca, como se pode verificar na Tabela 4.

Tabela 4

Valor médio da importância atribuída aos fatores por ciclo de ensino

\begin{tabular}{ccccccc}
\hline Fator & \multicolumn{2}{c}{2 CEB } & \multicolumn{2}{c}{3 CEB } & \multicolumn{2}{c}{ SEC } \\
\hline & M & SD & M & SD & M & SD \\
\hline Aprendizagem & 3.96 & 0.66 & 4.04 & 0.68 & 3.98 & 0.58 \\
Técnica/Fitness & & & & & & \\
Trabalho de Equipa & 3.97 & 0.82 & 3.86 & 0.84 & 3.56 & 0.88 \\
Libertar Energia & 3.05 & 0.88 & 3.23 & 0.84 & 3.44 & 0.77 \\
Estatuto & 2.83 & 0.88 & 2.73 & 0.88 & 2.50 & 0.89 \\
Socialização & 3.39 & 0.86 & 3.54 & 0.81 & 3.60 & 0.76 \\
Influência Extrínseca & 2.95 & 0.90 & 2.73 & 0.84 & 2.42 & 0.70 \\
\hline
\end{tabular}

A comparação entre os três níveis de ensino, para cada um dos fatores, permitiu constatar que existem diferenças significativas para todos os fatores, exceto para a Aprendizagem Técnica/Fitness, $F(2.1014)=1.560, p$ $=0.211$. As comparações realizadas permitiram encontrar diferenças, estatisticamente significativas, para os fatores Influência Extrínseca, $F(2.1014)=32.76, p \leq .001$, Trabalho de Equipa, $F(2.1013)=19.53, p \leq .001$, Estatuto, $F(2.1014)=11.35, p \leq .001)$, Socialização, $F(2.1014)=5.25, p=.005$, e Libertar Energia, $F(2.1014)=15.99, p \leq .001$.

Para o fator Trabalho de Equipa, os valores médios são mais baixos à medida que o ciclo de escolaridade aumenta, sendo as diferenças significativas quando a comparação é realizada entre os alunos do segundo ciclo e os alunos do secundário $(p \leq .001)$ e entre os alunos do terceiro ciclo e os alunos do secundário $(p \leq$ $.001)$.

As motivações para a prática desportiva, relacionadas com a Libertação de Energia, apresentaram diferenças significativas entre todos os níveis de escolaridade, sendo os valores médios mais altos à medida que o ciclo de escolaridade aumentava $\left(p \leq .001\right.$, comparando o $2^{\circ}$ ciclo com o Secundário; $p=.015$, comparando os dois ciclos de ensino básico e comparando o $2^{\circ}$ ciclo de ensino básico com o Secundário, $p$ $=.003$ ).

No que respeita aos motivos associados à Influência Extrínseca, estes apresentaram diferenças significativas entre todos os níveis de escolaridade, apresentando valores médios mais baixos à medida que o ciclo de escolaridade aumenta $(p=.001$, comparando os dois ciclos de ensino básico entre si e $p \leq .001$, nas restantes comparações).

A importância das questões relacionadas com o Estatuto, nas motivações para a prática desportiva, foi significativamente diferente em função do ciclo de escolaridade dos alunos. Assim, os alunos do ensino secundário apresentaram valores médios mais baixos, quando comparados com os dois ciclos de ensino básico ( $p \leq .001$ e $p=.001$, respectivamente). Não foram encontradas diferenças significativas entre os dois ciclos de ensino básico. No que se refere à influência do ciclo de escolaridade dos alunos nas questões ligadas à Socialização, apenas uma diferença significativa foi encon- 
trada $(p=.005)$, sendo esta entre o $2^{\circ}$ ciclo de ensino básico e o secundário, apresentando, os últimos, um valor médio mais alto.

\section{Motivos de Participação em função do Género}

Analisando as motivações para a prática Desportiva em função do género, verificou-se que os aspectos que assumem maior importância, para ambos os géneros, são a Aprendizagem Técnica/Fitness e o Trabalho de Equipa. A Tabela 5 apresenta o valor médio da importância atribuída aos fatores por género.

\section{Tabela 5}

Valor médio e desvio-padrão (M, SD) da importância atribuído aos fatores por género

\begin{tabular}{ccccc}
\hline Fator & \multicolumn{4}{c}{ Feminino Masculino } \\
& M & SD & M & SD \\
\hline Aprendizagem Técnica/Fitness & 3.86 & 0.67 & 4.11 & 0.61 \\
Trabalho de Equipa & 3.76 & 0.83 & 3.82 & 0.89 \\
Libertar energia & 3.22 & 0.80 & 3,27 & 0.87 \\
Estatuto & 2.37 & 0.82 & 2.92 & 0.87 \\
Socialização & 3.47 & 0.81 & 3.55 & 0.81 \\
Influência Extrínseca & 2.58 & 0.81 & 2.79 & 0.85 \\
\hline
\end{tabular}

A comparação dos fatores motivacionais para a prática desportiva, em função do género, permitiu constatar que existem diferenças estatisticamente significativas para a Aprendizagem Técnica/Fitness, $T(1014)=6.36, p \leq .001$, Influência Extrínseca, $T(1014)=3.92, p \leq$ .001 , e o Estatuto, $T(1014)=10.13, p \leq .001$, tendo o género feminino apresentado um valor médio menor em todos estes motivos.

\section{Motivos de Participação em função da Idade}

Foi possível estabelecer um perfil de associação entre os fatores motivacionais para a prática desportiva e a idade dos alunos. Assim, todos os fatores apresentaram uma associação estatisticamente significativa com a idade, exceto a Aprendizagem Técnica/Fitness, como se pode constatar na Tabela 6 .

Foi possível identificar uma associação significativa, no mesmo sentido, entre a idade dos alunos e a valorização do Estatuto $(p=.002)$, Socialização $(p=.015)$ e Libertação de Energia $(p \leq .001)$. Assim, à medida que aumentava a idade dos alunos, verificava-se um aumento do valor de importância atribuída pelos alunos a estes fatores. Pelo contrário, verificou-se a existência de uma relação inversa, ou seja, à medida que aumentava a idade dos alunos, verificava-se uma diminuição do valor de importância atribuída à Influência Extrínseca $(p \leq .001)$ e ao Trabalho de Equipa $(p \leq .001)$.

A Aprendizagem Técnica/Fitness não apresentou uma associação estatisticamente significativa com a idade $(p=.379)$.

\section{DISCUSSÃO}

A circunstância de, por um lado, a procura do conhecimento dos motivos que levam as pessoas a decidir praticar uma determinada modalidade física ou desportiva ser uma das áreas mais estudadas nos últimos anos (Barroso et al., 2007; Fonseca \& Ribeiro, 2001; Lores et al., 2004; Machado et al., 2005; Marzinek \& Neto, 2007; Ullrich-French \& Smith, 2006; Sirard et al. 2006) e, por outro, o desejo de caracterizar a população estudantil no que se refere às suas motivações, considerando a diferenciação em função do género, da idade e do nível de escolaridade, esteve na origem da realização deste estudo.

A análise das respostas dos inquiridos revelou que, de um modo geral, os motivos considerados como mais importantes para a

Tabela 6

Correlação de Spearman: Valor do Coeficiente de Correlação e significância da correlação dos factores com a idade

\begin{tabular}{ccccccc}
\hline Idade & Estatuto & $\begin{array}{c}\text { Técnica/ } \\
\text { Fitness }\end{array}$ & $\begin{array}{c}\text { Influência } \\
\text { Extrínseca }\end{array}$ & $\begin{array}{c}\text { Trabalho } \\
\text { Equipa }\end{array}$ & Socialização & $\begin{array}{c}\text { Libertar } \\
\text { energia }\end{array}$ \\
\hline Coeficiente de Correlação & .099 & -.028 & -.211 & -.170 & .076 & .181 \\
Sig. (2-tailed) & .002 & .379 & .000 & .000 & .015 & .000 \\
\hline
\end{tabular}


decisão de praticar desporto foram os relacionados com a procura de desenvolvimento das suas competências físico-desportivas, nomeadamente, para melhorar as suas competências técnicas específicas dessa modalidade e para manterem ou melhorarem os seus índices físicos. Ao invés, os motivos respeitantes à tentativa de aquisição de um estatuto elevado perante as outras pessoas foram os que exerciam menos impacto na sua decisão de praticarem desporto. Estes resultados são semelhantes aos que têm sido encontrados na generalidade dos estudos referenciados na literatura (Cruz \& Cunha, 1990; Fonseca \& Ribeiro, 2001; Gill et al., 1983; Klint \& Weiss, 1987; Longhurst \& Spink, 1987).

A literatura sobre a influência da idade na estrutura motivacional não parece ser, ainda, como se constata, totalmente clara. Se, por um lado, muitos autores identificaram a idade como variável diferenciadora (Afonso et al., 2001; Biddle, 1995; Biddle \& Mutrie, 2001; Fernandes, 2001; Fonseca, 1995; Fonseca \& Fontaínhas, 1993; Fonseca et al., 1998; Gould et al., 1982; Rebelo \& Mota, 1994), no que respeita às conclusões daí resultantes, estas são, por vezes, contraditórias. No presente estudo, verificou-se que, à medida que aumentava a idade dos alunos, registava-se um aumento do valor de importância atribuída ao Estatuto, Socialização e Libertação de Energia, enquanto que a importância atribuída à Influência Extrínseca e ao Trabalho de Equipa diminuía. Afonso et al. (2001) verificaram que as raparigas de idade inferior a 19 anos valorizavam mais os motivos relacionados com a Forma Física e o Prazer. Fonseca e Fontaínhas (1993) referem que os mais novos dão mais importância aos aspectos relacionados com o Estatuto, Grupo, Libertação de Energia, Divertimento e Amigos, o que contraria os resultados aqui obtidos. Rebelo e Mota (1994) referem que os praticantes com idades compreendidas entre os 16 e os 25 anos assinalam que praticam a modalidade como forma de fazerem amizades, de ultrapassarem desafios e de se divertirem. Balbinotti et al. (2007), num estudo realizado com uma amostra de 428 adolescentes do sexo masculino, com idades entre 13 e 16 anos, concluíram que a motivação relacionada com o prazer não variava de forma significativa durante a adolescência.

A análise dos valores relativos às dimensões motivacionais em função do género dos inquiridos, permitiu verificar que o género feminino apresentou um valor médio menor na Aprendizagem Técnica/Fitness, Influência Extrínseca e Estatuto quando comparado com o género masculino. Os resultados do presente estudo são consistentes com os de outros estudos, onde se verificou uma diferenciação em função do género (Barroso et al., 2007; Chantal, Guay, Dobreva-Martinova, \& Vallerand, 1996; Fonseca \& Fontaínhas, 1993; Gill et al., 1983; Kilpatrick et al. 2005; Longhurst \& Spink, 1987; Machado et al. 2005; Pelletier et al., 1995; Sirard et al. 2006). Fonseca (1995) corrobora as conclusões aqui obtidas, mencionando que, de uma forma geral, as raparigas dão menos importância aos motivos relacionados com a realização e o estatuto pessoal, enquanto Kilpatrick et al. (2005) verificaram que os homens atribuem maior importância a motivos intrínsecos relacionados com o ego e a performance e as mulheres dão maior relevância a motivos extrínsecos associados à imagem e à saúde. Machado et al. (2005) referem que o género masculino indicou motivos relacionados com a saúde, enquanto que o feminino referiu o divertimento. Resultados diferentes foram encontrados por Lores et al. (2004), tendo o género feminino valorizado os motivos relacionados com a saúde, enquanto o masculino referira os motivos relacionados com a competição. Os motivos relacionados com a competição e com a sociabilidade, na investigação conduzida por Balbinotti e Capazzoli (2008), eram mais valorizados pelo género masculino. Allen (2003) refere que a motivação para a prática de atividade física relacionada com o prazer não varia de forma signifi- 
cativa entre os géneros durante a adolescência.

Globalmente, a importância atribuída aos fatores motivacionais para a prática desportiva variou em função do ciclo de escolaridade, tendo-se verificado que existiram diferenças significativas para todos os fatores, exceto para a Aprendizagem Técnica/Fitness.

No Trabalho de Equipa, os valores médios são mais altos em ciclos de escolaridade mais baixos. Resultados semelhantes foram encontrados por Fonseca, Sousa, e Vilas-Boas (2001), referindo, estes, que o estabelecimento de contactos com outras pessoas assume, nestas idades, uma importância significativa, constituindo-se o Desporto como um meio privilegiado para este efeito. As motivações relacionadas com a Libertação de Energia apresentaram valores médios mais altos à medida que o ciclo de escolaridade aumentava, enquanto que a Influência Extrínseca, mostrava valores médios mais baixos à medida que o ciclo de escolaridade aumentava. Estes dados acompanham a idade. Como era de esperar, existe correlação elevada entre idade e nível de escolaridade e uma percentagem considerável de variância para estas variáveis colineares.

A importância atribuída ao Estatuto variou em função do ciclo de escolaridade dos alunos, sendo que, os alunos do ensino secundário apresentaram valores médios mais baixos. No que se refere à influência do ciclo de escolaridade dos alunos nas questões ligadas à Socialização, o $2^{\circ}$ ciclo de ensino básico apresentou um valor médio mais baixo que o secundário. Sousa (2004) verificou que, para os alunos do segundo ciclo, os motivos mais importantes são os motivos associados à afiliação, desenvolvimento de competências, prazer e forma física e que não existem diferenças nas motivações para a prática desportiva entre os alunos do terceiro ciclo e os alunos do ensino secundário, facto que não se verificou no presente trabalho.

\section{CONCLUSÕES}

A motivação dos alunos para a prática desportiva parece estar associada a um conjunto de variáveis demográficas que a determinam, variando com a idade, o nível de escolaridade e o género. A motivação para as aprendizagens e o fitness, para o trabalho em equipa, bem como para a socialização, num clima de motivação intrínseca, é assinalável correspondendo às fontes mais importantes de motivação. Considerando o incremento em idade e nível de escolaridade, existe uma diminuição da motivação para o trabalho de equipa e para a influência de terceiros sobre a motivação para a prática. Por outro lado, as motivações associadas ao estatuto social, aos processos de socialização e de libertação de energia ganham importância crescente com a idade e o nível de escolaridade. Já no que se refere ao género, as raparigas apresentam valores menores na motivação referente às aprendizagens técnicas e ao fitness, na motivação em função do estatuto social e nas influências extrínsecas para a prática. No entanto, não se encontraram diferenças, relativamente aos rapazes, nas motivações para o trabalho em equipa, para a socialização e para a libertação de energia.

O corrente estudo reconhece a importância de aprofundar a investigação que envolva o estudo das determinantes motivacionais da prática desportiva, face aos resultados contraditórios de boa parte da investigação realizada. Por outro lado, fruto da crescente diferenciação cultural na nossa sociedade, estudos interculturais, considerando outras variáveis de diferenciação demográfica presentes na população de alunos e de praticantes desportivos, deverão ser considerados. O nível sócio-económico e cultural, a etnia e a nacionalidade, entre outras variáveis, devem ser incorporados em modelos explicativos da motivação para a prática, considerando, nomeadamente, a interação entre essas variáveis. Por outro lado, outros modelos teóricos devem ser incorporados e contrastados com o modelo adotado neste estudo, de modo a se poder conhecer melhor a estrutura multifactorial das motivações dos praticantes despor- 
tivos. Em futuros estudos importa, ainda, adotar abordagens qualitativas, que permitam penetrar mais profundamente nas estruturas motivacionais, nas suas determinantes psicológicas e nas relações que estabelecem com os contextos e conteúdos das práticas.

\section{Agradecimentos:}

Nada declarado.

\section{Conflito de Interesses:}

Nada declarado.

\section{Financiamento:}

Nada declarado.

\section{REFERÊNCIAS}

Afonso, A., Fernandes, A., Soares, D., \& Fonseca, A. (2001). Estudo exploratório sobre os motivos que levam as pessoas a praticar aeróbica, In A. Fonseca (Ed.), Estudos sobre Motivação (pp. 88-91). Porto: FCDEF.

Alderman, R. (1976). Incentive motivation in Sport: An interpretative speculation of research opportunities. In A. C. Fisher (Ed.). Psychology of sport: Issues $\mathcal{E}$ insights. Palo Alto, California: Mayfield.

Alderman, R. (1978). Strategies for motivating young athletes. In W. F. Straub (Ed.). Sport Psychology: An analysis of athlete behaviour (pp. 136-148). Ithaca: N.Y. Movement.

Alderman, R. \& Wood, N. (1976). An analysis of incentive motivation in young Canadian athletes. Canadian Journal Applied Sport Science, 1, 169-176.

Allen, J. (2003). Social Motivation in Youth Sport. Journal of Sport \& Exercise Psychology, 25, 551-567.

Balbinotti, C., Barbosa, M., Juchem, L., Balbinotti, M., \& Saldanha, R. (2007). A motivação à prática de atividade física regular relacionada ao prazer em adolescentes do sexo masculino. Coleção Pesquisa em Educação Física, 6(2), 7-12.

Balbinotti, M., \& Capazzoli, C. (2008). Motivação à prática regular de atividade física: Um estudo exploratório com praticantes em academias de ginástica. Revista Brasileira de Educação Física e Esporte, 22(1), 63-80.

Barroso, M., Araújo, A., Keulen, G., Braga, R., \& Krebs, R. (2007). Motivos de prática de esportes coletivos universitários em Santa Catarina. In Fórum Internacional de Esportes, Anais, 6, (pp. 11.1-11.9). Florianópolis: Unesporte.

Biddle, S. (1995). Exercise Motivation Across the Life Span. In S. Biddle (Eds.), European Perspectives on Exercise and Sport Psychology (pp. 3-21). Champaign: Human Kinetics.

Biddle, S. (1998). Sport and exercise motivation: A brief review of antecedent factors and psychological outcomes of participation. In K. Green \& K. Hardman (Eds.), Physical Education: A reader (pp. 154-183). Aachen, Germany: Meyer \& Meyer.

Biddle, S., \& Mutrie, N. (2001). Psychology of Physical Activity: Determinants, well-being and interventions. London: Routledge.

Chantal, Y., Guay, F., Dobreva-Martinova, T, \& Vallerand, R. J. (1996). Motivation and elite performance: An exploratory investigation with Bulgarian athletes. International Journal of Sport Psychology, 7, 172-182.

Cid, L. (2002). Alteração dos motivos para a prática desportiva das crianças e jovens. Educación Física $y$ Deportes. Retrieved from http://www.efdeportes.com/efd55/motiv.htm.

Cruz, J., Costa, F., Rodrigues, R., \& Ribeiro, F. (1988). Motivação para a prática e competição desportiva. Revista Portuguesa de Educação, 1(2), 113-124.

Cruz, J., \& Cunha, A. (1990). Avaliação Psicológica. Sete Metros, 7, 52-58.

Fernandes, R. (2001). A motivação para a prática de natação de competição em atletas pré-juniores e juniores-seniores In A. Fonseca (Ed.), Estudos sobre a motivação (pp. 74). Porto: FCDEF.

Fonseca, A. (1995). Motivos para a prática desportiva: Investigação desenvolvida em Portugal, AGON - Revista crítica de desporto e educação física, 1, 49-62.

Fonseca, A., \& Fontaínhas, M. (1993). Participation motivation in portuguese competitive gymnastic. 
Paper presented at the Congresso Mundial de Ciencias de la Actividad y el Deporte, Granada: Universidad de Granada, F.C.A.F.

Fonseca, A., \& Maia, J. (1996). Análise factorial confirmatória à versão portuguesa do Participation Motivation Questionnaire. In A. Fonseca (Ed.). Estudos sobre a motivação (pp. 62-63). Porto: FCDEF.

Fonseca, A., \& Ribeiro, R. (2001). Motivos para a prática de trampolins: Um estudo com atletas de Elite. In A. Fonseca (Ed.), Estudos sobre a motivação (pp. 11-13). Porto: FCDEF.

Fonseca, A., \& Soares, J. (2001). Orientações cognitivas e para a prática de andebol. In A. Fonseca (Ed.), Estudos sobre a motivação (pp. 45-49). Porto: FCDEF.

Fonseca, A., Freitas, N., \& Frade, V. (1998). Estudo da relação entre a idade dos atletas e os seus motivos para a prática do futebol em equipas federadas da região de Coimbra. In A. Fonseca (Ed.), Estudos sobre a motivação (pp. 92-94). Porto: FCDEF.

Fonseca, A., Sousa, M., \& Vilas Boas, J. (2001). Motivos apresentados pelos jovens para a prática de natação de uma forma competitiva. In A. Fonseca (Ed.), Estudos sobre Motivação (pp. 88-91). Porto: FCDEF.

Frias, J., \& Serpa, S. (1991). Factores de motivação para a actividade gímnica no quadro da ginástica geral, ginástica de manutenção e ginástica de representação. In J. Bento, \& A. Marques (Eds.). As Ciências do Desporto e a Prática Desportiva, 1, 169-179.

Fry, D., McClements, J., \& Sefton, J. (1981). A report on participation in the Sasketoon Hockey Association. Saskatoon, Canada: Sask Sport.

Gill, D., Gross, J., \& Huddleston, S. (1983). Participation motivation in youth sports. International Journal of Sport Psychology, 14, 1-14.

Gould, D., Feltz, D., Weiss, M., \& Petlichkoff (1982). Participation motives in competitive youth swimmers. In T. Orlick, J. T. Partington, \& J. H. Salmela (Eds.), Mental training for coaches and athletes. Ottawa: Coaching Association of Canada.
Kilpatrick, M., Hebert, E., \& Bartholomew, J. (2005). College students' motivation for physical activity: Differentiating men's and women's motives for sport participation and exercise. Journal of American College Health, 54(2), 87-94.

Klint, K., \& Weiss, M. (1987). Perceived competence and motives for participating in youth sports: A test of Harter's competence motivation theory. Journal of Sport Psychology, 9, 55-65.

Koivula, N. (1999). Sports Participation: Differences in motivation and actual participation due to gender typing. Journal of Sports Behavior, 22, 360-376.

Kolt, G., Driver, R., \& Giles, L. (2004). Why older Australians participate in exercise and sport. Journal of Aging and Physical Activity, 12, 185-198.

Longhurst, K., \& Spink, K.(1987). Participation motivation of Australian children involved in organized sport. Canadian Journal of Sports Sciences, 12(1), 24-30.

Lores, A., Murcia, J., Sanmartín, M., \& Camacho, A. (2004). Motivos de práctica físico-desportiva según la edad y el género en una muestra de universitarios. Apunts, 76, 13-21.

Machado, C., Piccoli, J., \& Scalon, R. (2005). Fatores motivacionais que influem na aderência de adolescentes aos programas de iniciação desportiva das escolas da Universidade Luterana do Brasil. Educación Física y Deportes. Retrieved from http://www.efdeportes.com/efd89/inic.htm.

Marzinek, A., \& Neto, A. (2007). A motivação de adolescestes nas aulas de educação física. Educación Física y Deportes. Retrieved from http:// www.efdeportes.com/efd105/ motivacao-de-adolescestes-nas-aulas-de-educacao-fisica.htm.

Paim, M., \& Pereira, E. (2004). Fatores motivacionais dos adolescentes para a prática de capoeira na escola. Revista Motriz, 100(3), 159-166.

Pelletier, L., Tuson, D., Fortier, M., Vallerand, R., Briere, N., \& Blais, M. (1995). Toward a new mesure of intrinsic motivation, extrinsic motivation and motivation in sports: The Sport Motivation Scale (SMS). Journal of Sport \& Exercise Psychology, 17(1), 35-53.

Pereira, J., \& Vasconcelos-Raposo, J. (1998). As 
Motivacões e a Prática Desportiva. Análise descritiva, factorial e comparativa dos motivos e factores motivacionais parar a participacão e a não participacão desportiva de jovens do concelho de Baião. In A. Fonseca (Ed.), Estudos sobre Motivação (pp. 78). Porto: FCDEF.

Rebelo, M., \& Mota, J. (1994). Estudo comparativo das motivações para a prática da natação como actividade física de lazer numa população juvenil e adulta. (Dissertação de Mestrado). Porto: FCDEF.

Samulsky, D. (1992). Psicologia do Esporte: Teoria e Aplicação Prática. Belo Horizonte: Imprensa Universitária/UFMG.

Santana, M., \& Mota, J. (1994). Estudo comparativo para a prática da natação como actividade física de lazer numa população juvenil e adulta. (Dissertação de Mestrado). Porto: FCDEF.

Sapp, M., \& Haubenstricker, J. (1978). Motivation for joining and reasons for not continuing in youth sport programs in Michigan. Paper presented at the American Association of Health, Physical Education and Recreation National Convention. Kansas City: Missouri.

Serpa, S. (1992). Motivação para a prática desportiva: Validação preliminar do questionário de motivação para as actividades desportivas (QMAD). In F. Sobral, \& A. Marques (Coordenadores), FACDEX: Desenvolvimento somato-motor e factores de excelência desportiva na população escolar portuguesa, 2, 89-97. LOCATION: PUBLISHER.
Sousa, M. (2004). O Desporto Escolar no Concelho de Viseu: Que Realidade, que Motivação dos Jovens para a sua Prática? (Dissertação de Mestrado). Porto: FCDEF

Sirard, J., Pfeiffer, K., \& Pate, R. (2006). Motivational factors associated with sports participation in middle school students. Journal of Adolescent Health, 38, 696-703.

Trembath, E., Szabo, A., \& Baxter, M. (2002). Participation motives in leisure center physical activities. Athletic insight: The online journal of sports psychology, 4(3), 28-41.

Ullrich-French, S., \& Smith, L. (2006). Perceptions of relationships with parents and peers in youth sport: independent and combined prediction of motivational outcomes. Psychology of Sport and Exercise, 7(2), 193-214.

White, S., \& Duda, J. (1994). The relationship of gender, level of sport involvement, and participation motivation to task and ego orientation. International Journal of Sport Psychology, 25, 4-18.

Zahariadis, P., \& Biddle, S. (2000). Goal orientations and participation motives in Physical Education and Sport: Their relationship in English Schollchildren. International Journal of Sport psychology, 30, 223-243.

(c) EY-No Todo o conteúdo da revista Motricidade está licenciado sob a Creative Commons, exceto quando especificado em contrário e nos conteúdos retirados de outras fontes bibliográficas. 